\title{
GERENCIAMENTO DE PRODUTIVIDADE INDUSTRIAL APLICANDO O PILAR TÉCNICO WORK ORGANIZATION DO WORLD CLASS MANUFACTURING
}

\author{
Fábio da Silva Alves ${ }^{1}$; Ugo Ibusuki ${ }^{1}$ \\ ${ }^{1}$ Universidade Federal do ABC - UFABC - São Paulo - Brasil \\ E-mails: falveslhp@gmail.com, ugo.ibusuki@ufabc.edu.br
}

\section{RESUMO}

A constante busca por melhorias de produtividade nos processos de manufatura das indústrias estimulam o desenvolvimento de diferentes tipos de ferramentas e sistemas de gestão visando cada vez mais à eficiência e inovação. Ferramentas oriundas do Sistema Toyota de Produção (TPS), que têm como objetivo conter e reduzir os desperdícios, ao longo do tempo sofreram alguns aprimoramentos nas práticas enxutas gerando uma filosofia de trabalho, hoje comumente conhecida como Manufatura Enxuta (Lean). Algumas organizações obtiveram o sucesso com a sua implantação, e muitas outras sentiram e ainda sentem dificuldades de adoção desse sistema por não saber como, quando e onde utilizar cada uma das ferramentas. Seguindo os princípios da filosofia Lean e uma evolução desse sistema, o World Class Manufacturing busca o mínimo custo do processo, melhoria continua e pessoal capacitado, no qual seu gerenciamento é divido em pilares gerenciais e técnicos para um melhor entendimento e implementação. Dessa forma, o presente trabalho busca focar na análise de um dos pilares técnicos, o de Organização do Posto de Trabalho, que está diretamente ligado à redução de perdas e desperdícios, e ao aumento de produtividade nas indústrias, instruindo para um melhor gerenciamento e demonstrando através de um estudo de caso.

\section{INTRODUÇÃO}

Evidencia-se atualmente no cenário econômico mundial um ambiente volátil que constantemente influenciam as organizações numa competitividade acirrada gerando um grande desafio para a manutenção das mesmas no mercado, sendo extremamente necessário as constantes mudanças. É visto como primordial para a sobrevivência organizacional a inovação, no qual o seu processo estratégico envolve a criação de novos modelos de negócios, processos organizacionais, meios de competição e cooperativismo empresarial, e práticas para atender as necessidades dos consumidores, sendo assim, um importante artifício para a diferenciação nesse cenário competitivo e globalizado. Entretanto, poucas organizações tem a iniciativa de praticá-la, sendo justificada por uma provável visão ultrapassada sobre a inovação ou por desconhecimento das ferramentas e processos.

Womack, Jones e Ross (1992) mostram que essa busca por competitividade pode ser observada em momentos distintos da história, e de extrema importância para $\mathrm{o}$ surgimento de novas tecnologias, como por exemplo, o desenvolvimento e fixação do 
sistema de produção em massa fordista no início do século XX. Esse modelo, que até então era o sistema mais eficiente apresentado - mesmo com alguns problemas relacionado a perdas e desperdícios - deu origem a um estudo desenvolvido e liderado por Taiichi Ohno da Toyota. Através deste estudo foi possível compreender os processos e as estratégias dos competidores, reconhecendo seu impacto na cultura organizacional, e assim, promover melhorias e adaptações necessárias para própria realidade, com o objetivo de eliminar as perdas dos processos. Nascia o denominado Sistema Toyota de Produção (TPS) [1].

Shingo (1996) mostra que o TPS foi construído conciliando simultaneamente uma teoria geral de produção, no qual o sistema de produção constitui de uma rede funcional de processos e operações, e uma testagem empírica da teoria via uma lógica de tentativa e erro [2]. Com o passar dos anos o sistema foi evoluindo e ganhando corpo, além de surgirem outras nomenclaturas para defini-lo. A mais usual foi estabelecido por Womack et al (1992) que utilizou o termo Lean Manufacturing - que traduzido significa Manufatura Enxuta (ME) - para descrever de forma abrangente todo o sistema de negócio da Toyota, no qual designava o TPS um modelo de práticas enxutas por utilizar menos elementos para produção, como por exemplo, espaço fabril, esforço humano, estoques, horas de desenvolvimento de materiais, entre outros, e dessa forma atingir uma redução significante de custos [1]. De fato, o TPS ou Lean Manufacturing, demonstrou historicamente o poder de construir uma potente estratégia dentro da competição capitalista, já que a Toyota se tornou a maior montadora do mundo.

Diante desse cenário de sobreviver às exigências do mercado aberto e ao mesmo tempo desenvolver inovação, as indústrias passam por um grande "teste de fogo". Produzir cada vez mais, com menos recursos e com qualidade superior à dos concorrentes, tornase uma condição de base para as organizações, que durante as últimas décadas tem adotado novas práticas de manufatura [3][4], e a prática mais evidente é justamente a Manufatura Enxuta. Shah e Ward (2003) consideram que a ME é uma abordagem multidimensional que inclui diversificadas práticas de gestão em um sistema integrado, que quando implementadas simultaneamente, geram uma sinergia de trabalho que procura satisfazer as necessidades do cliente, além de combater as adversidades e os diversos tipos de desperdícios [5].

Todavia, adotar a ME como filosofia de cultura organizacional não é tão simples quanto parece. A própria Toyota não impôs esse sistema na sua organização, foi algo que emergiu naturalmente de forma empírica durante as décadas devido às necessidades, sequer o sistema foi passado para o papel e muitas vezes nem mesmo funcionários da empresa conseguem explicar de forma coerente, sendo esse um dos principais motivos para a não compreensão nítida desse sistema. Muito dos observadores e gestores confundem as ferramentas e práticas que veem com o sistema propriamente dito, e afirmam que o processo para implementação da filosofia em si é demorado, carente de um ótimo planejamento [4][6][7][8][9]. Dessa forma, torna-se praticamente impossível para eles resolverem um paradoxo evidente do sistema - a saber, que as atividades, as conexões e os fluxos de produção em uma fábrica da Toyota são rigidamente roteirizados ao mesmo tempo em que suas operações são tremendamente flexíveis e adaptáveis. As atividades e processos são constantemente desafiados e pressionados a atingir um nível mais alto de desempenho, para garantir que a empresa continue a inovar e a melhorar. 
A partir destas considerações, um questionamento pode ser levantado: haveria possibilidade que as organizações adotassem novos métodos de sistema de gestão de forma a se manter competitivo, compreendendo e aplicando de uma maneira mais nítida e eficiente as ferramentas e práticas de uma Manufatura Enxuta sem que houvesse uma mudança brusca e repentina, ou seja, que pudesse aplicá-la de forma planejada, coerente e fragmentada em secções (uma área de trabalho modelo dentro da produção, por exemplo), reduzindo os desperdícios, obtendo um ganho inerente desse processo e consequentemente mudar a sua ótica concerne à mudança de cultura organizacional?

A realidade é que existe uma lacuna a ser explorada em termos de desenvolvimento de novos métodos, porém isso não remete que não haja uma evolução referente a ME. Os estudos dentro do próprio sistema desenvolveram transformações a decorrer do tempo, como por exemplo, o Seis Sigma e o World Class Manufacturing (WCM).

A metodologia WCM apresentada por Richard Schonberger e desenvolvida pelo Dr. Hajime Yamashina é um sistema de gestão integrado de redução de custos e visa otimizar as principais bases industrial para níveis de classe mundial: Logística, Qualidade, Manutenção e Produtividade. Para isso, a estrutura metodológica do sistema é dividida em pilares gerenciais e técnicos, permitindo um sistema coeso de gerenciamento, responsável pelo planejamento, desenvolvimento, acompanhamento, além de coordenar as atividades durante a aplicação do modelo auxiliando o alcance dos objetivos dos pilares técnicos; o outro ponto destacável é a descontinuidade como chave diferencial, isto é, permite a aplicação das práticas e ferramentas em áreas modelos e posteriormente a expansão, o que resulta num maior controle e confiabilidade para a integração do sistema como um todo. Desta maneira, o sistema que se baseia na implementação na íntegra dos princípios do TPS tem como objetivo: combater sistematicamente cada desperdício e perda existente em toda a cadeia (clientefabricante-fornecedores); no envolvimento das pessoas e respectivos desenvolvimento de suas competências; e na utilização de práticas que são apropriadas para a eficiência do processo de fabricação [10][11].

Tendo a possibilidade de aplicar um sistema de gestão que se mostra inovador devido a suas práticas, adentrando essa lacuna a ser explorada, para que assim, possibilite organizações adequem seus processos de manufatura visando a redução de custos e desperdícios, e consequentemente a melhoria contínua, o foco do presente trabalho procura contribuir para uma gestão qualificada envolvendo o segmento de produtividade (uma das quatro bases do $\mathrm{WCM}$ ), já que este é o principal indicador no processo de manufatura, e aplicar os conceitos específicos do WCM com o objetivo de orientar as organizações para a implementação do sistema.

\section{LEVANTAMENTO BIBLIOGRÁFICO}

No início do século passado o recurso estratégico e a diferenciação para competividade foram baseadas no processo de produção das organizações, no qual a transição foi de uma produção que era realizada por encomenda com grande lead time e mão de obra qualificada para uma produção em massa, estabelecida por Henry Ford, reduzindo o custo unitário dos produtos. $\mathrm{O}$ sistema perdurou por algumas décadas, mas enfrentava os mais diversificados problemas, como por exemplo, aumento dos níveis de inventário, alto investimento para maquinário, ausência de variedade de produto, entre outros. Com uma grande agitação e constante mudança do mercado, as organizações sentiram a 
necessidade de transitar para novos sistemas e métodos de conduzir sua produção. Analisando profundamente o fluxo da cadeia do modelo fordista através de um benchmarking, Taiichi Ohno após demasiadas observações sobre o sistema apontou algumas deficiências no processo, como por exemplo, materiais excedentes em estoque e diversas interrupções com longos períodos na linha de produção. A ideia foi aproveitar o fluxo de peças na linha, melhorando demais aspectos, inserindo dois pilares importantes para esse processo: o Just in Time e o Jidaka. Esses conceitos foram a base para que a Toyota atingisse uma produção boa o suficiente para suportar a variabilidade de produtos e a redução dos desperdícios dentro de toda a cadeia [12].

A princípio o sistema sofreu resistências, principalmente por parte dos operadores que deveriam ser polivalentes, porém foi gradualmente implantado e sofrendo alterações ao longo da implementação. Shingo (1996) mostra que o sistema foi uma testagem empírica da teoria via uma lógica de tentativa e erro. Para Spear e Bowen (1999), a Toyota tem um método científico enraizado na sua estrutura, e independente da mudança a ser realizada, esta passa por uma avaliação meticulosa e é elaborado um plano de melhoria, tornando-se um rigoroso processo de resolução de problemas, além do envolvimento e comprometimento das pessoas que compõe a organização, tornado um ciclo que estimula os próprios para experimentação e inovação [2][7]. Logicamente o sucesso desse sistema levanta o interesse de outras organizações, e reflete em diversos estudos e melhorias pertinentes a sua evolução, não permitindo que o sistema fique estagnado como aconteceu com o modelo fordista.

Coexistem várias definições para a $\mathrm{ME}$, porém evidencia-se que muitas organizações confundem a filosofia da ME com algumas ferramentas que a compõem. Ghinato (1995) relata que alguns autores caracterizam a ME sendo JIT, como pode ser visto no trabalho de Meredith e Shafer (2002), demonstrando uma superficialidade e falta de entendimento da verdadeira essência do sistema. Essa confusão pode ser atribuída ao fato do JIT ser um grande diferenciador da produção tradicional para esse sistema, desse modo, os termos são tratados como sinônimos [4][6][8]. Ainda outros autores mostram que tal confusão é existente e que muitas organizações navegam na superfície desse sistema, focando apenas em algumas ferramentas para atender à necessidade em curto prazo, uma vez que, não existem regras para a adoção dessas ferramentas. Desta forma, há também a falta de compreensão da essência filosófica que deve estar inserida na cultura organizacional, no qual os personagens, por terem limitação no entendimento dos conceitos e benefícios, acreditam que existem inúmeros problemas nas práticas enxutas [9][13][14].

É de concordância entre muitos autores que a implementação da ME têm como ponto de partida a compreensão por completa do sistema, uma preparação da organização em diferentes níveis de colaboradores, para posteriormente usar as técnicas abordadas no Lean, e que devido a sua complexidade, deve-se implementar num processo à longo prazo, não encurtando o tempo ou tratando como uma implantação de máquina, por exemplo [2][13][15][16].

Outro ponto fundamental para o sucesso da ME é o envolvimento e comprometimento da alta gestão, incentivando a criatividade e ideias inovadoras, pois é um processo laborioso e custoso gerar determinadas mudanças em relação a certos costumes e atitudes que são barreiras dentro das organizações, principalmente quando a mudança é de forma radical. Mazzone (1993) relata ainda que as organizações brasileiras sofrem 
com barreiras de aspectos culturais e educacionais dificultam a adoção de processos enxutos [9][15][16][17][18].

Identificamos quatro pontos que influenciam significativamente na adoção da $\mathrm{ME}$, indo de encontro com o trabalho de Albuquerque (2008): dificuldades na compreensão, adaptação e desenvolvimento de procedimentos e ferramentas; tempo de implantação em longo prazo; envolvimento e suporte da alta gestão; e resistência à mudança cultural. Um ponto significativo, em concordância a aspectos levantados neste trabalho está relacionado à falta de uma metodologia para implementação do sistema. Tendo em vista que a ME foi desenvolvida naturalmente e não passou por um processo de roteirização, tornando por muitas vezes inexplicável seu funcionamento, onde o processo de implementação navega por uma nebulosidade.

Levando também em consideração Spear \& Bowen (1999), no qual concluem que numa organização onde pessoas podem desenvolver e aplicar as mudanças de projeto sem afetar outras partes têm grandes chances de sucesso de implementar um sistema de gestão eficaz, delegando responsabilidades sem criar caos [7]; surge a oportunidade de verificar uma nova metodologia para um gerenciamento das práticas enxutas, sobre tudo, voltado para a produtividade dos processos de manufatura. Assim, apresentamos o WCM, que além da metodologia estruturada, propõe a criação de uma área modelo (servindo de projeto-piloto) que serve como um exemplo de aplicabilidade do sistema, permitindo um importante processo para convencimento e exposição à mudança da cultura organizacional.

\subsection{WORLD CLASS MANUFACTURING}

O intuito do presente trabalho é descrever apenas sobre um dos pilares técnicos que compõe o WCM, o pilar Workstation Organization (WO) - Organização do Posto de Trabalho - que está diretamente ligado a produtividade industrial, e descrevendo brevemente sobre os pilares gerenciais que são base para os pilares técnicos.

O WCM é um sistema inovador de gestão baseado em melhoria contínua, cujo foco é a eliminação de todos os tipos de desperdícios e perdas de produção através do envolvimento de todos os níveis e departamentos. O objetivo é ter alta produtividade com produtos de alta qualidade respondendo às necessidades dos clientes, garantindo a máxima flexibilidade e custos competitivos, buscando a excelência em um mercado competitivo. Além disso, desenvolve conhecimentos capazes de reeducar as pessoas para ações de prevenção e de melhoria contínua, garantindo o aumento da confiabilidade dos equipamentos e da capabilidade dos processos, sem grandes investimentos adicionais [19][20]. O sistema foi baseado nas práticas desenvolvidas do TPS, mas foi Hajime Yamashina o grande difusor do WCM nas organizações, descrevendo-o como nível de excelência de todo ciclo logístico e produtivo, além de estabelecer uma metodologia estruturada para implementação do sistema. De acordo com Yamashina (2007) o sistema foi baseado em conceitos de filosofias gerenciais já existentes - como mostrado na figura 1 - que integrados e trabalhando simultaneamente geram o mínimo custo para produção e contribuem substancialmente para o desempenho operacional, formando a base do sistema: Total Productive Maintenance; Total Quality Control; Just in Time; Total Industrial Engineering. [12][21][22][23]. 


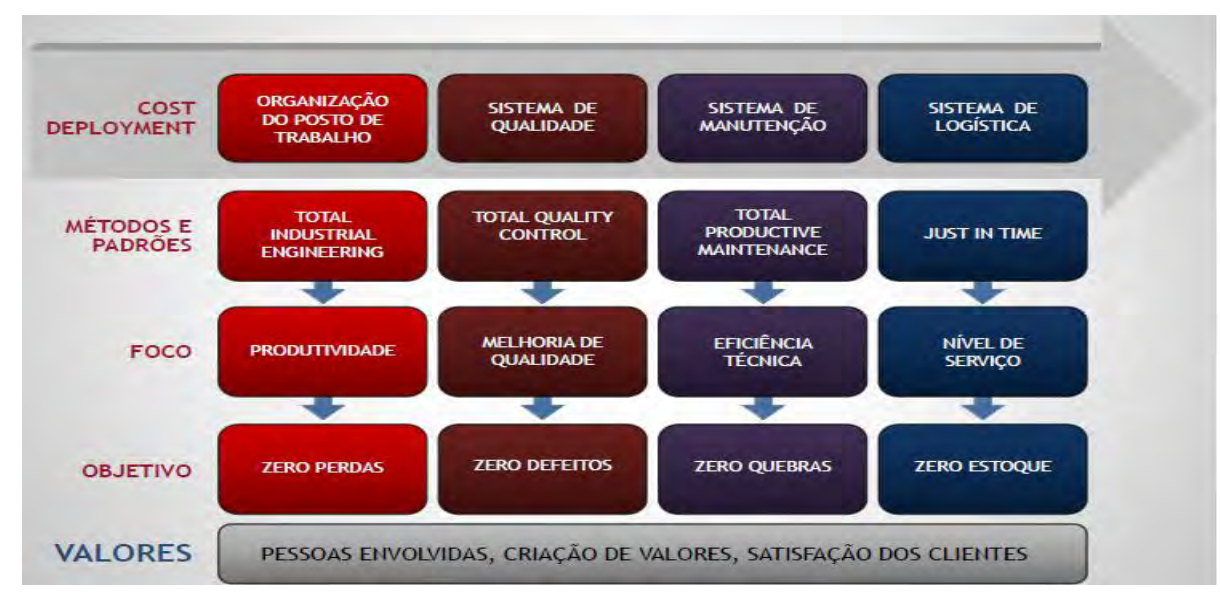

Figura 1 - Quadro de unificação das filosofias. Fonte: Material interno de aplicação WCM (2014).

Rubrich (2004) enfatiza que o sistema deve ser difundido em toda fábrica seguindo uma filosofia Top-Down, ou seja, comprometimento da alta gestão até o chão de fábrica. Segue-se dez princípios básicos: segurança primeiro; padronização é igual a melhoria; voz do cliente; target zero; aplicação rigorosa dos métodos; o WCM é visual; é desenvolvido no chão de fábrica; aprender fazendo; envolvimento de pessoas; energia em crise [22]. Os benefícios de integrar o WCM à organização incluem o aumento da competitividade, desenvolvimento de novas tecnologias, maior flexibilidade, melhor comunicação entre gestão e produção e aumento da qualidade do trabalho [10]. As atividades e práticas são distribuídas em dez pilares gerenciais e dez pilares técnicos, seguindo uma metodologia estruturada que facilita a implementação do WCM.

Os pilares gerenciais indicam o comprometimento que as pessoas e a organização devem demonstrar durante a aplicação do modelo para auxiliar o atendimento dos objetivos dos pilares técnicos. São eles: compromisso no gerenciamento; clareza nos objetivos; mapeamento de rota de aplicação; alocação de pessoas altamente qualificadas; comprometimento da organização; competência da organização; tempos e recursos financeiros; nível de detalhamento; nível de expansão; motivação dos operadores. Cada pilar gerencial tem subcritérios para avaliação [24].

Os pilares técnicos estão relacionados aos processos de produção com cada um contendo objetivos específicos para o desenvolvimento do sistema na organização. Para a implementação correta de cada um dos pilares técnicos são subdivididos em sete passos (step-by-step) para atingir o êxito no programa (CORTEZ, 2010). Os pilares técnicos são: Segurança (SAF); Desdobramento de Custos (CD); Melhoria Focada (FI); Atividades Autônomas - sendo este pilar subdividido devido sua complexidade em Manutenção Autônoma (AM) e Organização do Posto de Trabalho (WO); Manutenção Profissional (PM); Controle de Qualidade (QC); Logística e Serviço ao Cliente (LCS); Gestão Antecipada de Equipamentos (EEM); Desenvolvimento de Pessoas (PD); Meio Ambiente (ENV) [24].

\subsection{WORKSTATION ORGANIZATION (WO)}


O pilar WO é constituído de um conjunto de critérios técnicos, métodos e instrumentos para criar uma estação de trabalho em condições ideais. Isso significa realizar ações de restauração e de melhoria contínua com o objetivo de garantir a ergonomia e a segurança da estação de trabalho com o mínimo de movimentação de materiais, assegurar a qualidade dos produtos mediante um processo robusto, e principalmente a melhoria da produtividade, aplicando as ferramentas apropriadas para otimização e criação de padrões de trabalho de modo que o comportamento dos operadores possa garantir a repetibilidade do processo. O resultado previsto das atividades desenvolvidas através do pilar consiste na redução significativa dos principais tipos de desperdício que levam a não qualidade do produto, redução de produtividade, melhoria consistente da ergonomia e na substancial redução de movimentação de materiais [24].

As perdas e desperdícios se assemelham, porém com abordagens diferentes para resoluções de cada uma, focando em gestão de ativos e gestão de fluxos e materiais respectivamente. As perdas são privações de recursos que ocorrem durante os processos. Já os desperdícios são definidos como a quantidade de recursos utilizados em excesso com relação aos requisitos necessários para produzir um valor constante de produção. As sete categorias segundo Shingo (1985) são as seguintes: superprodução; tempo de espera; transporte; perdas de processo; estoque; defeitos; movimentos [25].

Do ponto de vista da produção enxuta, o conceito de valor é referente as atividades necessárias que compõe os requisitos dos produtos/serviços aos clientes, sendo classificadas em: atividades que agregam valor (VAA), que são atividades que converte materiais e/ou informações em direção ao que é exigido pelo cliente; e atividades que não agregam valor (NVAA) que são atividades que demandam tempo, recursos ou espaço, gerando custos diretos ou indiretos, mas não adicionam qualquer valor do ponto de vista do cliente. As NVAA's podem ser divididas em atividades contributivas e improdutivas, sendo que as contributivas geralmente são necessárias e essenciais na execução de uma operação, como por exemplo, manuseio de materiais no local de trabalho, trabalhos auxiliares de posicionamento de produto, entre outras; e as improdutivas são as não necessárias, como a ociosidade de algum operador enquanto uma operação está sendo executada. As NVAA's, em média, representam uma grande parte das atividades inerentes aos processos de produção, e por isso devem ser tomadas medidas para o controle parcial ou total eliminação [24][26][27].

\section{ESTUDO DE CASO}

O estudo de implementação do referente trabalho foi realizado numa empresa multinacional que adota a filosofia WCM, facilitando o processo de aprendizado e aplicação satisfatória através da realização de benchmarking em outras empresas do grupo à qual pertence.

Assim como todos os pilares técnicos, o pilar WO consiste de sete passos para implementação completa, divididos em fases reativa, preventiva e proativa, como demonstrado na figura 2. A cada passo efetuado, em conjunto com os outros pilares, 
ocorrem auditorias para avaliar o aproveitamento e dar prosseguimento na prática. Entretanto a implementação do pilar pode ser efetuada de forma segmentada.

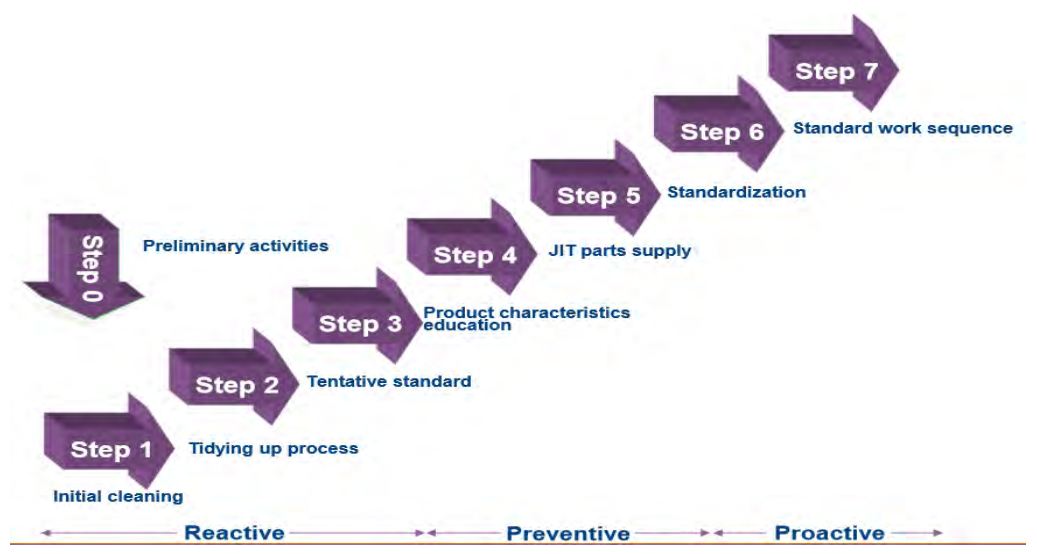

Figura 2 - Estrutura de implementação do pilar WO do WCM. Fonte: Material interno WCM (2014).

\subsection{STEP 0 - ATIVIDADES PRELIMINARES}

As atividades preliminares são necessárias para a correta atuação nas estações de trabalho, onde são realizados informativos sobre o sistema para que haja a conscientização das pessoas envolvidas e os caminhos para atingir os objetivos e sucesso do programa, além de treinamentos sobre segurança e as mais variadas ferramentas que compõe a ME, como por exemplo, $5 \mathrm{WlH}$, 5 Why's, $5 \mathrm{~S}$, aplicação da Tag's (etiquetas indicativas de não conformidade), ferramentas da qualidade, entre outras (se possível agregando os Pilares WO, SAF e PD). Todas as diretrizes devem ser aplicadas e gerenciadas pelo gestor responsável pelo sistema, o plant manager, pois este deve deter os conhecimentos dos pilares gerenciais e consequentemente os técnicos, uma vez que a filosofia do sistema é difundida seguindo um procedimento top-down [22][24].

Em paralelo aos treinamentos, duas importantes análises devem ser realizadas para iniciar a aplicação do pilar: a estratificação valorizada de todas perdas da fábrica através de um gráfico de Pareto (denominada Matrix C), como por exemplo, NVAA's, quebras de máquinas, falta de matéria-prima, setups, entre outros; e a estratificação das causas-defeitos que é dada através da Matriz QA (Quality Assurance), que conforme Yamashina é uma ferramenta utilizada para os estudos das condições atuais do controle da qualidade que relaciona a frequência de ocorrência dos defeitos, os custos relacionados, os reparos dos defeitos e o nível de gravidade. Uma observação importante está relacionada a uma boa coleta de dados da fábrica de tal forma que seja confiável, uma vez que esses dados serão os direcionadores para a identificação das causas e da área modelo - geralmente as estratificações são feitas pelo $\mathrm{CD}$, sendo uma bússola para demonstrar os lugares que devem ser atacados pelos demais pilares técnicos para implementar melhorias, com constantes acompanhamentos [24].

Como citado, o foco principal do pilar WO é reduzir as perdas e desperdícios que estão diretamente relacionadas as áreas de trabalho dos operadores, influenciando diretamente na baixa produtividade, qualidade e processos de retrabalhos. Com isso, a principal perda que deve ser focada por este pilar são as NVAA's juntamente com os defeitos de qualidade. Posteriormente esta 
totalização de perdas, realiza-se uma nova estratificação para verificar qual o posto de trabalho que detém as maiores perdas e desperdícios, e assim, escolhemos a maior para ser a área modelo. As áreas de expansão são dividas da seguinte forma: AA - é a área que corresponde a $50 \%$ do total de perdas total; A - até $70 \%$; B - até $90 \%$; e C cobrindo $100 \%$.

Para esse trabalho foi escolhido como área modelo três prensas - denominadas Prensa 31, Prensa 33 e Prensa 36, cuja suas características são semelhantes - de compactação de pó metálico, que fabricam peças da mesma família, pertencentes ao processo de sinterização. Estas prensas operam a um tempo máquina médio de 6 peças por minuto, no qual este tempo é equivalente ao tempo de ciclo, ou seja, todas as operações do ciclo realizadas pelos operadores são feitas enquanto a máquina trabalha. São dispostos dois operadores MOD (mão-de-obra direta) por turno para executar as atividades deste posto de trabalho mais o auxílio de um operador logístico (MOI - mão-de-obra indireta) que realiza as movimentações de matéria-prima até as estações de trabalho, efetuando essa operação em outras 31 máquinas de compactação, ou seja, utiliza-se nesta estação de trabalho 3/34 da mão de obra desse operador. Então, nas condições iniciais temos duas MOD mais 0,09 MOI, três máquinas que produzem 360 peças por hora cada, resultando numa produtividade de 517 peças/operador/hora.

Ainda nas atividades preliminares é definida a equipe de WO pela alta gestão, sendo composta por pessoas que tenham conhecimento e habilidade usuais para o crescimento do Pilar, dividida nas fases reativa, preventiva e proativa (cada fator exige ferramentas de conhecimentos específicos) por meio do Radar Chart (ferramenta gráfica que avalia competência individual e da equipe pontuando os conhecimentos em cada ferramenta da ME). É necessário que a equipe detenha o máximo conhecimento na fase reativa para a implementação, e adquirindo o conhecimento para as demais fases através de treinamento educacional. O líder do pilar WO deve estabelecer então um Plano Diretor (Master Plan) que é um programa/cronograma que serve para planejar e verificar o desenvolvimento da implementação de acordo com as áreas, bem como as atividades relacionadas ao pilar. No entanto, pode ser gerenciado de forma colaborativa por toda a equipe devido à grande gama de atividades.

São dois indicadores que mensuram o andamento da implementação: o KPI (Key Performance Indicator) e o KAI (Key Activity Indicator). Os KPI's são os mantidos para todo processo, medindo produtividade, benefício/custo (B/C) e qualidade (First Time Quality). Já os KAI's são variados de acordo com cada passo. Esses indicadores além de permitir o visual sobre cada passo, servem também como avaliação para os processos de auditorias (mínimo de 85\%) [24].

\subsection{STEP 1 - LIMPEZA INICIAL}

Inicialmente devemos aplicar o 5S para a organização e padronização de limpeza no posto de trabalho, identificando as anomalias sinalizadas pela Tag's (etiquetas), que são cartões preenchidos com causas ou motivos recorrentes de anomalias, e posteriormente fixados individualmente no local onde foi encontrada cada anomalia, classificando as fontes de contaminação (mapa de contaminação), os defeitos de qualidade, e os problemas apresentados, 
compilando num quadro com as listas de anomalias para a posterior elaboração de um programa de resolução. Essas atividades envolvem todos os operadores da área modelo que são guiadas pelo líder do pilar da unidade operacional.

Ao final desse step obtivemos uma remoção de mais 400 quilos de materiais excessivos desnecessários para o processo de fabricação, além da melhoria na aparência das máquinas, padronização de limpeza diária (antes e pós-ciclo de trabalho). Foram identificadas como fontes de contaminação o vazamento de mangueiras hidráulicas de óleo e água, e principalmente o excesso de pó metálico na estação de trabalho, listando as ocorrências para planejar melhorias aplicadas no próximo passo. Os indicadores destacados neste passo apontaram um $\mathrm{B} / \mathrm{C}$ de 0,9 , devido alguns pequenos gastos fora do orçamento, porém com um aproveitamento de $94,4 \%$ de $T a g$ 's realizadas.

\subsection{STEP 2 - REORGANIZAÇÃO DO PROCESSO}

Primeiramente são tomadas algumas contramedidas em relação às fontes de contaminação para que elas sejam contidas ou eliminadas. Para a contenção das fontes de água e óleo foram necessárias manutenções corretivas e programadas nas conexões e tubulações dos fluídos e nas unidades hidráulicas dos equipamentos. Em relação ao pó metálico foi fundamental o desenvolvimento de projetos que reduzam a contaminação principalmente nas esteiras de saída das prensas, onde haviam um alto grau de sujeira ocasionado pela compactação da matéria-prima. Foram fabricados dois dispositivos para reduzir a propagação: um dispositivo de sucção nas esteiras de saída de peças e uma caixa coletora de pó no final das esteiras, reduzindo a sujeira que se instalava no chão. Ao final da implantação dos dispositivos obtivemos uma redução de 6 minutos de limpeza por turno, correspondendo a um saving de 13 mil reais anuais e um $\mathrm{B} / \mathrm{C}$ de 6,3 .

Posteriormente a atenção está voltada para o processo com o objetivo de melhorar as condições de trabalho, nas reduções de erros e consequentemente, melhoria de produtividade, efetuando-se análise relacionando todas as atividades de operação e classificando-as. Em sequência, usa-se o Yamazumi Chart devido sua representação visual para evidenciar o desbalanceamento existente na célula de trabalho, separando as atividades que agregam e não agregam valor com os seus tempos. Esse gráfico serve para comparar o takt time, isto é, o tempo que se deve produzir uma peça ou produto baseado no ritmo de vendas, para atender a demanda dos clientes. Fornecem informações importantes para as análises de Muri, Mura e Muda [26][29],cuja finalidade é a eliminação de desperdícios ocasionados por atividades que não agregam valor ao processo. Para isso as atividades são divididas em três grupos: VAA - atividades que agregam valor, geralmente atividades de transformação do produto; SVAA - atividades de semivalor agregado, não agregam valor, mas são indispensáveis no processo, como por exemplo, posicionar uma peça; NVAA - atividades que não agregam valor, sendo essas a causa dos desperdícios, como por exemplo, caminhar, transportar, esperar, etc. Importante compreender que essas ferramentas são complementares para a eliminação dos desperdícios, utilizando-se da filmagem dos movimentos para uma melhor observação. Exemplo: quando um processo está desbalanceado ou sem padrão (Mura), observa-se a ocorrência de sobrecarga de equipamentos e pessoas (Muri) e consequentemente teremos os tipos de NVAA's, ou seja, 
desperdícios (Muda). Na figura 3 mostramos através do Yamazumi Chart a condição inicial do posto de trabalho relacionando as atividades dos operadores com o tack time.

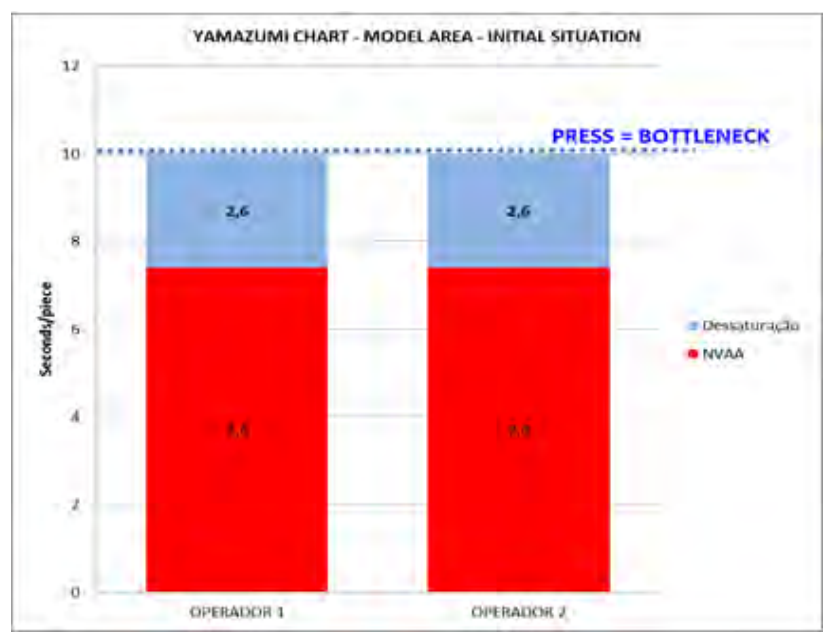

Figura 3 - Gráfico Yamazumi da área modelo - situação inicial. Fonte: Dados da empresa (2016).

O Muri é um conjunto de operações que consiste de movimentos de difícil execução ou não naturais que possam gerar fadiga e incluir riscos aos funcionários, como por exemplo, fadiga muscular (operação de força ou posição incoerente), fadiga mental ou fadiga emocional. Essas operações difíceis também reduzem a produtividade do trabalho e suas análises são feitas aplicando a disciplina de ergonomia. No caso, relaciona-se as atividades realizadas pelos operadores com o tipo de movimento: verde (nível 3) onde nenhuma intervenção deve ser efetuada; amarelo ou laranja (nível 2) onde é recomendado a supervisão dessas atividades; e vermelho (nível 1) onde é extremamente necessário realizar medidas corretivas. Para realizar essa classificação existe uma tabela de ergonomia para auxiliar [26][28][29].

Na nossa área modelo foram constatados 42 tipos de movimentos na operação, que basicamente consiste em paletizar as peças compactadas: pegar uma bandeja vazia e colocá-la sobre uma mesa fixa; preencher a bandeja com as peças compactadas; colocar bandeja cheia no local de "peças conformes" para o prosseguimento das operações. A maioria das atividades foram classificados como nível 1 (30 movimentos), e pós análise projetamos um plano de ação para corrigir e eliminar os desperdícios. Foi instalado então, um elevador próximo à exaustão de peças compactadas e melhoria nas disposições das bandejas. Ao todo obtivemos a eliminação dos movimentos de nível 1, e redução de $50 \%$ dos de nível 2, tendo ao fim, 14 movimentos para a operação de paletização.

O Mura é aplicado em sequência verificando as operações irregulares devido à falta de padronização, isto é, operações realizadas de distintas maneiras gerando diferentes resultados no ciclo de trabalho. A análise procura identificar os responsáveis que impedem a execução regular do ciclo, intervir para solucionar o problema e padronizar novos métodos de trabalho, sendo que uma das principais causas está relacionada à colocação incorreta dos materiais e das ferramentas. Alguns critérios eficazes são tomados para evitar a ocorrência de 
operações irregulares, como por exemplo, mesma altura das mesas de trabalho, simplicidade nos movimentos de trabalho (pegar, repor, deslocar, etc.) [28][29].

No posto de trabalho observamos que dos quatro operadores responsáveis pelas atividades (dois operadores por turno), um deles levava mais tempo que os outros para realizar a atividade de paletização das peças na bandeja, devido à falta de padronização do método de trabalho. Para solucionar a variação que estava ocorrendo na linha na atividade de paletização, foi sequenciado um método de trabalho e padronizado utilizando a SOP (Procedimento Operacional Padrão), que é uma ferramenta usada para descrever a execução correta das tarefas, demonstrando detalhadamente através de imagens e textos explicativos 0 passo-a-passo. Os operadores são treinados para que haja a familiaridade com o processo, e em caso de dúvidas, a SOP pode ser consultada na própria estação de trabalho, onde é fixada dentro do campo visual do operador.

O Muda consiste em operações que não agregam valor aos processos gerando desperdícios e que devem ser identificados, quantizados, estratificados, para que posteriormente possamos tomar ações para a eliminação. Tivemos no posto de trabalho como maiores índices de NVAA as seguintes atividades: caminhar $(49 \%)$, esperar $(26 \%)$, inspecionar $(15 \%)$, limpar $(8 \%)$, posicionar $(2 \%)$. Para atacar a maior perda, o caminhar (geralmente uma das maiores perdas nos processos de produção), utiliza-se uma ferramenta específica chamada Spaghetti Chart no qual é uma representação gráfica dos deslocamentos efetuados pelos operadores durante a execução do ciclo de trabalho e a partir daí desenvolver uma análise detalhada para a otimização da movimentação dos materiais e dos movimentos das pessoas. O gráfico geralmente é desenhado sobre um layout que facilita a identificação das movimentações [9].

Para resolver o problema de Muda existente, identificamos que para a execução das tarefas os operadores percorriam em média 768 metros por turno, na sua maioria, para alimentação dos bag's de pó metálico e o revezamento entre as operações das máquinas. Estabelecemos duas propostas juntamente com o Pilar LSC para resolução: a primeira foi a alocação de outro operador logístico responsável pelo transporte de peças compactadas para estoque em processo destinado para a próxima operação, além da alimentação de pó metálico nas máquinas, sendo que este faz essa operação nas 34 máquinas de compactação; e a instalação de uma esteira coligando as três prensas, diminuindo bruscamente a perda de caminhar para operá-las - mostrado através do gráfico (figura 4) o antes e depois da implementação do projeto.

O projeto obteve um $\mathrm{B} / \mathrm{C}$ de 3,9 e um saving de 87 mil reais, reduzindo a NVAA caminhar de $49 \%$ para $13 \%$ do tempo total. 


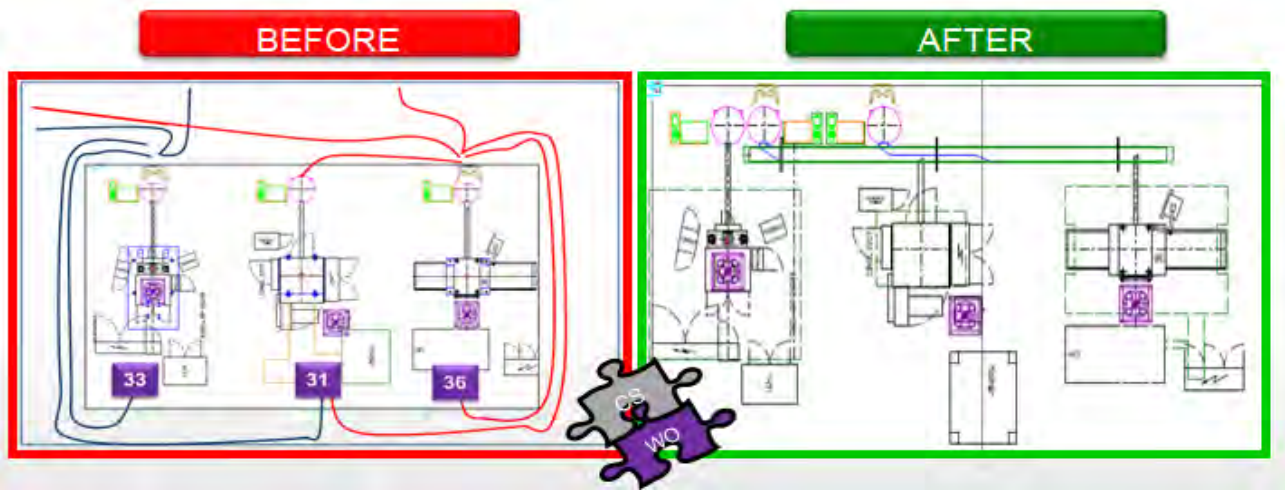

Figura 4 - Gráfico Spaghetti antes e depois das propostas de melhoria. Fonte: Dados da empresa (2017).

Juntamente com estas melhorias uma nova análise visando a área de atuação dos operadores é realizada, com ferramentas específicas denominadas Golden Zone e Strike Zone, divididas em níveis de acordo com a proximidade que os produtos se encontram com os operadores, deixando-os mais próximos possíveis para uma operação mais linear e sem riscos ergonômicos. Ao final do step $2 \mathrm{com}$ as melhorias estabelecidas, pode-se reduzir em $83,6 \%$ do tempo de limpeza da estação de trabalho, uma redução de aproximadamente $50 \%$ das atividades que não agregam valor e $62 \%$ de dessaturação no processo, finalizando com um B/C total de 2,3. Entretanto houve um aumento de MOI rateada de 0,09 para 0,18, com a inserção de outro operador logístico.

\subsection{STEP 3 - PADRONIZAÇÃO INICIAL}

O objetivo deste passo é definir os padrões iniciais para manter o processo nas condições atingidas nos passos anteriores. Prevê a completa padronização não somente das operações que geram valor agregado sobre o produto, mas também de todas atividades auxiliares ligadas a correta gestão das estações de trabalho, dos materiais e das ferramentas, através de SOP e OPL (Lição ponto-a-ponto) que são ferramentas visuais das atividades.

A ideia é praticar o rebalanceamento da linha de produção de tal forma a distribuir as atividades entre os operadores para que estes não fiquem saturados durante o ciclo de fabricação, ou até mesmo se possível concentrar as atividades em operadores buscando a redução da quantidade destes na linha de produção, logicamente se a saturação não for excessiva. $\mathrm{Na}$ análise (pós aplicação de Muri, Mura e Muda) foi constatado um tempo de operação de 3,8 segundos/peça para cada operador da linha, resultando em 6,2 segundos de dessaturação, já que o tempo de gargalo da linha é de 10 segundos. Sendo assim, praticamos o rebalanceamento da linha de produção, concentrando todas as atividades em um único operador (mostrado na figura 5). Desse modo, um operador seguindo as atividades padronizadas pode distribuir seu tempo de operação para as três prensas, obtendo ainda um fator de recuperação de $25 \%$ por ciclo.

Com essas alterações atingimos um B/C de 14,7 e um saving de 179,6 mil reais, além de um aumento de 77,56\% em relação à produtividade, que passou de 517 (peças/operador/hora) para 918 (peças/operador/hora) e um FTQ de 96,79\% (este fator começou a ser utilizado após as mudanças e padronizações da linha). Em comparação com o step anterior reduzimos em 44\% o tempo de limpeza por 
turno, obtendo também um total de 32 OPL's e 23 SOP's, além da solução de $100 \%$ das Tag's e padronização nas atividades de limpeza e manutenção.

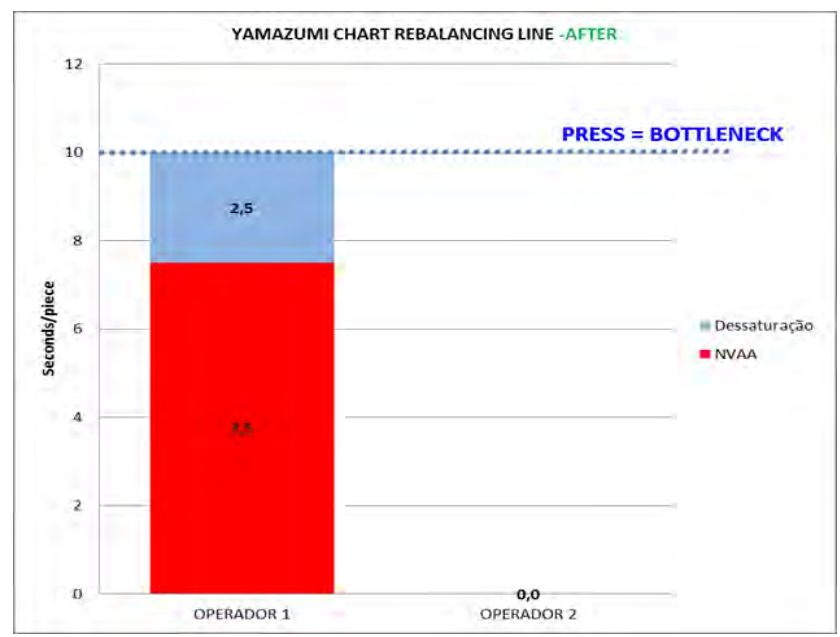

Figura 5 - Gráfico de Yamazumi - Rebalanceamento das atividades. Fonte: Dados da empresa (2017).

\subsection{STEP 4 - TREINAMENTO DO PRODUTO E CONTROLE}

Nesse passo é uma transição da fase reativa para a preventiva, composta por uma importante interação entre os Pilares WO, CQ e PD, pois objetivo aqui é aprender sobre a estrutura e função do produto, assegurando a qualidade da produção e a condução de uma inspeção geral dos utensílios, ferramentas e instrumentos de medição, bem como assegurar a qualidade dos resultados. Logo, os treinamentos proporcionam um aprendizado que aumentam o nível de capabilidade dos operadores, promovendo um incremento nos conhecimentos, de tal maneira a dar suporte para as demais áreas, além de contribuir para a identificação das causas-raiz de erros humanos.

As mais variadas ferramentas podem ser utilizadas nesse passo (conduzido pelo pilar QC, ou setor da Qualidade), onde a base é aumento do fator FTQ (First Time Quality), que é o cálculo da porcentagem de peças boas que se recebe no final da linha sem qualquer retrabalho e sucata. O WO trata de defeitos provenientes de erros humanos e problemas de método para aumentar FTQ, visando o "zero defeito" [24]. Além da nova análise da Matriz QA, faz-se juntamente a elaboração da ferramenta 4M, mais conhecida como Digrama Espinha-de-peixe ou Diagrama Ishikawa, para a classificação das causas associadas à Material, Máquina, Método e Mão de obra, sendo essas duas últimas o foco do pilar WO para atuação.

Outra ferramenta relevante é a $Q A$ Network, cujo é demonstrado num quadro para a melhor compreensão do tipo de controle que temos para defeitos específicos, incluindo a identificação da posição do controle em relação à ocorrência do defeito.

No step 4 foram levantados os dados em conjunto com o Pilar QC que resultou em um total de $52 \%$ das causas-efeitos para Métodos e Mão-de-obra, cujo tais defeitos são oriundos de erros humanos, determinando assim alguns projetos para reduzir ou eliminar tais defeitos, elevando o fator FTQ. Na Matrix $Q A$ 
elaborada podemos identificar a causa raiz do problema de qualidade enfrentado: arrancamento da aresta do dente da polia de comando durante o manuseio para o empilhamento na paletização. Como solução, foi desenvolvido um sistema pokayoke, que consiste num tampo na mesa giratório evitando o empilhamento casual. Obteve-se um B/C de 4,9 com um saving correspondente a 1,35 mil reais. Ao final, com as melhorias relacionadas aos métodos e mão de obra, e a aplicação do dispositivo, houve um incremento do FTQ para 98,46\%, além de ganhos intangíveis, como o aumento da conscientização dos operadores quanto aos méritos do controle da qualidade no próprio processo, a exemplo do que ocorre fazer no momento em que se apresenta um problema que pode incidir sobre a qualidade do produto.

\subsection{STEP 5 - FORNECIMENTO JUST IN TIME}

A demanda do cliente sempre muito diversificada e a crescente procura por um tempo de entrega reduzido fazem com que seja de vital importância desvincular o processo de transformação da abordagem convencional de produção de grandes lotes e tornar-se uma organização muito enxuta e flexível [17][28]. Sendo assim, o objetivo do passo cinco consiste em reduzir e eliminar as perdas devido à alimentação de material e aos movimentos dos operadores, desenvolvendo o fornecimento de JIT à estação de trabalho. Com isso, é indispensável a atuação em conjunto ao pilar LSC.

O ponto de escolha do componente para o operador na estação de trabalho deve ser revisado com a Golden Zone (AA, uma zona deve ser alvo, a zona B é aceitável) e o conceito de Strike Zone (zona de ataque), seguindo principalmente os princípios da economia de movimento que ajudam a reduzir a fadiga e aumentar a produtividade.

Rever a posição do material e o movimento das pessoas dentro e ao redor da linha de montagem e identificar uma combinação ideal, reduzindo o estoque em processo na linha e estabelecendo um balanceamento mais eficiente da linha de montagem para aumentar a flexibilidade da linha em toda a flutuação da demanda. O conceito LCA (Low Cost Automation) deve ser utilizado nesse passo, visando uma automação barata, simples e rapidamente implementável pelo operador que conhece o processo e o problema.

As principais atividades nesse processo são: realização de melhoria no projeto das tarefas de trabalho; introdução de potência de componentes onde for possível; disposição de todos os componentes sobre prateleiras na altura e na direção ideais; otimização das prateleiras dos componentes; manter um controle de componentes em estoque de modo que seja ideal; rever a disposição dos materiais e o movimento dos operadores e na área da linha de montagem para obter uma combinação ideal.

\subsection{STEP 6 - PADRONIZAÇÃO DO PROCESSO}

O objetivo do sexto passo consiste em reduzir e eliminar as perdas de NVAA residuais devido à falta de padrões, analisando os movimentos pequenos realizados pelo operador para otimizar e padronizar as operações. Rever e 
melhorar os padrões iniciais para torná-los mais simples: prevenir contra defeitos de qualidade; minimizar a operações irregulares; instituir uma operação rítmica de modo a minimizar a fadiga através de movimentos repetitivos, seguindo um ritmo natural; comparar os padrões iniciais com os procedimentos de trabalho produzidos com o objetivo de definir a rotina de trabalho padrão das operações.

\subsection{STEP 7 - EFETIVAÇÃO DA SEQUÊNCIA DE TRABALHO}

O último passo da implantação do Pilar WO consiste na efetivação do trabalho realizado, partindo das atividades de implementação da sequência de trabalho padrão para reduzir a variabilidade qualitativa; instalação do sistema operacional padronizado; obtenção de um processo flexível frente à variabilidade da produção; e desenvolvimento das habilidades dos operadores para satisfazer a necessidade do aumento de produção dos novos produtos.

\section{CONCLUSÃO}

Por via dos estudos realizados é evidenciado que as oscilações que o cenário econômico mundial navega gera nas organizações uma procura por diferenciação para a manutenção e competitividade das mesmas no mercado, e a estratégia escolhida pelas organizações de sucesso está por meio da inovação em diferentes âmbitos do modelo de negócio, como por exemplo, em técnicas e práticas de gestão em um sistema integrado visando à produção com excelência e satisfação do cliente, além do combate às adversidades e diferentes tipos de desperdícios existentes. Nas organizações industriais é nítido que o foco principal é o processo de manufatura, pois este detém as maiores perdas dentro do seu modelo de negócio. Logo, desenvolver um gerenciamento de produtividade é extremamente importante para a redução dos gastos e desperdícios para a fabricação dos produtos, mantendo-os com preços diminutos e com ótima qualidade, e dessa forma estabelecer um alto nível de competitividade e consequentemente sua manutenção no mercado.

Historicamente é comprovada que houve uma evolução no gerenciamento dos processos de manufatura onde maior a diferenciação de sucesso surgiu com a inclusão do TPS, tanto que foi modelo de estudo por diversos gestores, especialistas e cientistas, que buscavam desvendar e compreender o funcionamento do sistema que atualmente é conhecido Lean Manufacturing. Entretanto, a falta de metodologia para aplicar este sistema que foi simplesmente transformado sem roteiros, torna-se nebuloso para inúmeras pessoas que em alguns casos confundem os princípios e ferramentas com o sistema em si, uma vez que não há regras para aplicar tais ferramentas. Sendo assim, a falta de uma metodologia concisa de implementação para a utilização das ferramentas e principalmente da adoção do sistema integrado de gerenciamento, que navega por uma essência filosófica dentro da cultura organizacional da empresa, acaba influenciando negativamente para o entendimento do sistema e os benefícios que as práticas enxutas podem trazer as organizações.

O modelo de sistema estruturado e roteirizado do WCM demonstra-se eficaz para a compreensão e a implementação das práticas enxutas, além de utilizar a descontinuidade como chave diferencial, ou seja, a aplicação das práticas e ferramentas em áreas 
modelos, sem que haja uma mudança brusca na organização, e posteriormente pode-se utilizar os cases de sucesso nas áreas de expansão. Todavia, o foco do trabalho está no âmbito do gerenciamento de produtividade industrial, sendo que foi aplicado um dos pilares técnicos (WO) do sistema para demonstrar os benefícios e melhorias no local de trabalho, já que nas plantas fabris estão os maiores desperdícios das organizações.

A implementação do Pilar WO mediante a este trabalho foi possível até a finalização do step 4 , devido às datas programadas para aplicação da metodologia, e como o processo é trabalhoso há necessidade de tempo disponível para que os step's consequentes sejam aplicados com sucesso. Porém, visivelmente demonstramos o ganho de produtividade como foi proposto e outras melhorias significativas no posto de trabalho. Assim, no final desta aplicação adquirimos os seguintes indicadores mostrado na figura 6 :

\begin{tabular}{|c|c|c|c|c|c|c|}
\hline STEP & K.A.I & STEP 0 & STEP 1 & STEP 2 & STEP 3 & STEP 4 \\
\hline \multirow{5}{*}{$\begin{array}{l}\text { MODEL } \\
\text { AREA }\end{array}$} & $\begin{array}{l}\text { NUMBER OF WORKERS } \\
\text { DIRECT SNDD INDIRECT/ } \\
\text { SHIFT }\end{array}$ & $\begin{array}{c}2,00 \text { Direct } \\
+ \\
0,09 \text { Indirect }\end{array}$ & $\begin{array}{c}2,00 \text { Direct } \\
+ \\
0,09 \text { Indirect }\end{array}$ & $\begin{array}{c}2,00 \text { Direct } \\
+ \\
0,18 \text { Indirect }\end{array}$ & $\begin{array}{c}1,00 \text { Direct } \\
\stackrel{+}{+} \\
0,18 \text { Indirect }\end{array}$ & $\begin{array}{c}1,00 \text { Direct } \\
+ \\
0,18 \text { Indirect }\end{array}$ \\
\hline & DESATURATION & $x$ & $26 \%$ & $62 \%$ & $25 \%$ & $25 \%$ \\
\hline & TAG'S OPEN/CLOSED & $\mathrm{x}$ & $90 / 85$ & $130 / 123$ & $155 / 155$ & $197 / 197$ \\
\hline & OPL'S/ SOP'S & $x$ & $14 / 6$ & $14 / 12$ & $32 / 23$ & $42 / 28$ \\
\hline & $\begin{array}{c}\text { CLEANING TIME } \\
\text { (MIN/OPERATOR/ SHIFT) }\end{array}$ & $\mathrm{x}$ & 232 & 38 & 21 & 21 \\
\hline STEP & K.P.I & STEP 0 & STEP 1 & STEP 2 & STEP 3 & STEP 4 \\
\hline \multirow{3}{*}{$\begin{array}{l}\text { MODEL } \\
\text { AREA }\end{array}$} & $\begin{array}{c}\text { PRODUCTIVITY } \\
\text { (PÇS / WORKER / HOUR) }\end{array}$ & 517 & 517 & 496 & 918 & 918 \\
\hline & $B / C$ & $x$ & 0,9 & 2,29 & 14,71 & 4,92 \\
\hline & FTQ\% & $\mathrm{x}$ & $x$ & $\mathrm{x}$ & 96,79 & 98,46 \\
\hline
\end{tabular}

Figura 6 - Tabela de indicadores KPI E KAI no final de cada step. Fonte: Dados da empresa (2017).

No step inicial é demonstrado a importância do comprometimento da alta gestão sendo fundamental para o andamento da implementação do sistema, uma vez que a coordenação, suporte e acompanhamento das atividades são essenciais para a confiabilidade e o compromisso estabelecido no grupo, e desta maneira vai de encontro ao que foi citado por Liker (2016) e Blackstone, Cox \& Crawford (1988). Os treinamentos dos membros que compõe o grupo são indispensáveis, pois o conhecimento das práticas enxutas e do sistema são relevantes para a adaptação de uma nova cultura organizacional, daí novamente a ação dos gestores. Neste ponto a integração com os pilares de PD e SAF são de importância para desenvolver os treinamentos qualificados a concerne da segurança (segurança em primeiro lugar) e sobre as ferramentas utilizadas na fase reativa do pilar. Entretanto, tratamos apenas da aplicação do pilar WO, o que nada impede que esses treinamentos sejam realizados e coordenados por outros responsáveis setoriais (como Recursos Humanos e Segurança do Trabalho, por exemplo) de uma empresa que queira implementá-lo separadamente.

Da mesma forma, a integração com o pilar CD leva a mesma relevância, pois as estratificações dos custos e perdas sobre as áreas produtivas servem de bússola para a escolha da área modelo e áreas de expansão, além de detectar os pontos a serem 
atacados e a constante revisão. Neste caso, sem o suporte deste pilar, o andamento da implementação fica prejudicada, pois precisamos de informações seguras baseado em dados passados para definir a área de atuação. Logo, planeamento, elaboração e avaliação de dados contábeis a respeito da empresa devem ser levantados para direcionar o trabalho do pilar.

A maioria das ferramentas utilizadas já são existentes e muitas oriundas do TPS, o que facilita o entendimento teórico, e que são englobadas estrategicamente a cada step para que haja sintonia e sequenciamento de trabalho lógico. Os projetos desenvolvidos ao longo da implantação de cada step visaram sempre um benefício muito maior que o custo para aplicação, demonstrando a redução de custos e melhorias na qualidade de trabalho. Até mesmo ao final do step 2 onde foi inserido uma MOI para disponibilizar materiais para a produção obtivemos um ganho devido a projetos que melhoraram a qualidade de operação direta possibilitaram a uma maior dessaturação e consequentemente a concentração das atividades num único operador da linha produtiva. Essa ação foi primordial para que obtivéssemos uma melhor produtividade relacionada a peças/operador/hora, incrementando em 77,56\%.

Ao longo do step 4 (fase preventiva) foi indispensável a atuação em conjunto com o pilar QC devido a treinamentos sobre o conhecimento e a qualidade dos produtos, qualificando os operadores em relação ao seu nível de competência bem como para identificação das causas raízes referentes aos erros de métodos de trabalho e mão-deobra. Da mesma forma, há atuação em conjunto com o pilar LSC no step 5, para a disponibilidade de materiais em JIT reduzindo tempos e movimentos para o fornecimento de suprimentos e produtos propondo um planejamento adequado e melhorias na qualidade do serviço. Novamente destaco que nada impede destas ações serem em conjunto com setores responsáveis por qualidade e logística respectivamente, desde que, utilizem ferramentas mencionadas e em conjunto com outros setores ofereçam treinamento qualificados para a aprendizagem dos operadores. Porém devido ao período de estudo o prosseguimento do step 5 não foi possível, mas a estrutura teórica propõe ganhos significativos, assim como tivemos nos outros passos.

$\mathrm{Na}$ fase proativa é necessário a constante padronização e sequenciamento do trabalho, mantendo as revisões em periodicidade para a melhoria contínua, já que o sistema não é estacionário, e sim cíclico.

Deve-se ressaltar que pela empresa em questão ser adepta da filosofia do WCM, possibilitou o estudo de caso com uma maior facilidade dando o devido andamento e progresso da implementação do pilar de gerenciamento de produtividade. Com isso, sublinho que há grande possibilidade de empresas que queiram aplicar apenas o pilar WO sofrerem determinadas resistências à mudança cultural devido a radicalização, a fatores educacionais e culturais presentes na sociedade brasileira, como também foi destacado por Mazonne (1993) e Albuquerque (2008). Por isso o comprometimento de diretores e gestores com o sistema é essencial, devendo estabelecer um plano para a implementação, como por exemplo, verificar e avançar os step's a cada seis meses caso atendam uma autoavaliação de $90 \%$, e tratar o sistema à longo prazo, pois como foi afirmado por White (1993) o processo de implementação de práticas enxutas leva tempo e não pode ser tratada como uma implantação de uma máquina. 
Um ponto bastante considerável tange nas autoavaliações e auditorias externas, pois assim como em outros sistemas de gestão e de qualidade, pode haver uma determinada manipulação ou preocupação com o sistema apenas nas datas próximas a estas auditorias, deixando-o de lado para atender algumas necessidades impostas pelo mercado ou pela própria organização (como atender a outros indicadores, por exemplo), faltando com o comprometimento e indo na contramão da filosofia proposta. É preciso ter um senso crítico elevado e realmente estar disposto as mudanças e adaptações que são idealizadas, não temendo a busca pelo novo e encarando as dificuldades com sabedoria e planejamento estratégico. Não atender as demandas iniciais do sistema não significa incompetência da organização, e sim um esforço maior para corrigir costumes e falsas padronizações, parafraseando Taiichi Ohno: "onde não há padrão, não pode haver melhoria, e melhorar geralmente significa fazer algo que nunca fizemos antes".

Logicamente os pilares são dependentes uns dos outros para o prosseguimento harmônico, pois de uma forma macro o sistema visa o gerenciamento técnico da organização. Mesmo da forma focada para a produtividade como foi abordado é existente esse relacionamento com os demais pilares, entretanto nada impede que pequenas e médias organizações comecem a se estruturar e utilizar o método de gerenciamento de produtividade da manufatura através do pilar $\mathrm{WO}$, influenciando a adoção da filosofia do sistema e uma mudança cultural gradativa, já que os resultados são visíveis e a metodologia é de forma segregada, sem alterações bruscas nas organizações.

Com base nos estudos e resultados apresentados é possível utilizar um sistema de gerenciamento coeso e estruturado, permitindo a familiarização com práticas enxutas, permitindo a eliminação de perdas e melhorias de produtividade nas plantas produtivas, independentemente do tamanho das mesmas, desde que exista o envolvimento e comprometimento da alta gestão da organização e planejamento para a implementação do sistema gerencial, que é fundamental para o sucesso da filosofia e da mudança da cultura organizacional

\section{REFERÊNCIAS}

[1] WOMACK, J. P.; JONES, D. T. e ROOS, D. A máquina que mudou o mundo. 14. ed. Rio de Janeiro: Campus, 1992

[2] SHINGO, S. O sistema Toyota de produção. 2 ed. São Paulo: Bookman, 1996.

[3] HALL, Robert W. Attaining manufacturing excellence. McGraw-Hill, 1987.

[4] MEREDITH, Jack R.; SHAFER, Scott M. Administração da Produção para MBA's. 1 ed. Porto Alegre: Bookman, 2002. 391 p.

[5] SHAH, Rachna; WARD, Peter T. Lean manufacturing: context, practice bundles, and performance. Journal of operations management, v. 21, n. 2, p. 129-149, 2003.

[6] GHINATO, P. Sistema Toyota de Produção - mais do que simplesmente Just in Time. Revista Produção, v. 5, n. 2, p. 169-190, 1995.

[7] SPEAR, Steven; BOWEN, H. Kent. Decodificando o DNA do Sistema Toyota de Produção. Harvard Business Review, p. 97-106, 1999.

[8] ALBUQUERQUE, T. P., Manufatura enxuta: Dificuldades identificadas para implantação em indústrias de manufatura. Dissertação mestrado profissional Universidade Federal da Bahia, Escola de Administração, Salvador, 2008.

[9] LIKER, Jeffrey K. O modelo Toyota: 14 princípios de gestão do maior fabricante do mundo. Bookman editora, 2016. 
[10] FELICE, Fábio; PETRILLO, Antonella; MONFREDA, Stanislao. Improving Operations Performance with World Class Manufacturing Technique: A Case in Automotive Industry. Intech, Cassino, Itália, v. 1, n. 3, mar. 2013.

[11] DE CARVALHO MENDES, Rafael; DE MATTOS, Max Cirino. A World Class Manufacturing (WCM) e o desafio da gestão do conhecimento na ISO 9001: 2015. SAFRA LATACI ${ }^{\circledR}$, v. 6, n. 1, 2017.

[12] OHNO, Taiichi, O sistema Toyota de produção: além da produção em larga escala. 1 ed. São Paulo: Bookman, 1997.

[13] WHITE, Richard E. An empirical assessment of JIT in U.S. manufacturers. Production and Inventory Management Journal, Denton, v. 34, n. 2, p.38-42, 1993.

[14] ZIPKIN, P. H. Does manufacturing need a JIT revolution? Harvard Business Review. v. 69. n. 1, p. 40-46, 1991.

[15] EBRAHIMPOUR, Maling; LEE, Sang M. Just-in-time production system: some requirements for implementation. International Journal of operations \& production management, v. 4, p. 3-15, 1984.

[16] JUSTA, M. A. O da; BARREIROS, N. R. Técnicas de gestão do Sistema Toyota de Produção. Revista Gestão Industrial, Ponta Grossa-PR, v. 05, n. 01, p.01-17, 2009.

[17] BLACKSTONE JR J. H.; COX J. F; CRAWFORD K. M. A study of JIT implementation and operating problems. International Journal of Production Research. V. 26, p. 1561-1568, 1998

[18] MAZZONE, J. S. O sistema enxuto e a educação no brasil. J.A. Valente (org) Computadores e Conhecimento: Repensando a Educação. Campinas: Gráfica da UNICAMP. pp. 274-312, 1993

[19] MURINO, T. et al. A world class manufacturing implementation model. Applied mathematics in electrical and computer engineering, p. 978-1, 2012

[20] FREITAS, Isabel Siega; BARROS FILHO, Luis Cordeiro. Diagnóstico da implantação da Metodologia de Gestão Estratégica World Class Manufacturing (WCM) nas indústrias de Pernambuco. Revista de Engenharia e Pesquisa Aplicada, v.3, n.1, 2016

[21] PADDOCK, B. Top management's: Guide to World Class Manufacturing.1st ed. Kansas City: Buker, Inc., 1993.83 p.

[22] RUBRICH, L., WATSON, M. Implementing World Class Manufacturing. 2ed. Fort Wayne, Indiana, 2004.

[23] YAMASHINA, H. Challenge to world class manufacturing. International Journal of Quality of Reliability Management, Kyoto, v. 12, n. 34, p. 30-31, 2007.

[24] YAMASHINA, H. World Class Manufacturing: Métodos e instrumentos. Material interno de aplicação WCM da empresa em estudo, 2014.

[25] SHINGO, S. A revolution in manufacturing: the SMED System. Cambridge: Productivity Press, 1985

[26] ROTHER, M.; SHOOK, J. Aprendendo a enxergar: mapeando o fluxo de valor para agregar valor e eliminar o desperdício. São Paulo: Lean Institute Brasil, 1.Ed., 1998.

[27] BARNES, Ralph M., Estudo de movimentos e de tempos. Edgard Blücher, $6^{\mathrm{a}}$ ed, São Paulo, 1982.

[28] RODRIGUES, Marcus Vinicius. Entendendo, aprendendo e desenvolvendo sistemas de produção Lean Manufacturing. Elsevier Brasil, 2017.

[29] PIEŃKOWSKI, Maciej. Waste measurement techniques for lean companies. Int J Lean Thinking, v. 5, n. 1, 2014. 